\title{
Sistema pensional en Colombia y organismos económicos multilaterales: algunas perspectivas de reforma ${ }^{1}$
}

\section{Pension system in Colombia and multilateral economic organizations: Some reform perspectives}

\author{
Jaime Alberto Mejía Castrillón \\ Magíster en Seguridad Social \\ Universidad CES. Medellín, Colombia. \\ Correo electrónico: jaimea.mejia@udea.edu.co
}

\section{Resumen}

En la actualidad, el sistema pensional en Colombia atraviesa una seria crisis asociada a diversos factores, entre los que se encuentran la sostenibilidad del sistema, el envejecimiento poblacional, los bajos índices de cobertura, entre otros. Sin embargo, es posible advertir que esta crisis se remonta a los orígenes del sistema, donde la falta de previsión en la adopción de un modelo sostenible y con fallas estructurales generaron con el paso del tiempo problemáticas que amenazan su existencia.

Ante este panorama, han surgido desde distintos sectores y organismos de carácter político y económico iniciativas que pretenden hacer frente a la crisis. No obstante, estas propuestas implican serias reformas al esquema vigente además de encontrar algunas limitantes legales. Por lo anterior, el presente escrito analiza a través de un rastreo documental las propuestas de reforma al sistema general de pensiones que distintas organizaciones de carácter económico

1 Este artículo es producto de la investigación Reforma pensional en Colombia: orientaciones de los organismos económicos internacionales en el contexto normativo colombiano de la Maestría en Seguridad Social de la Universidad CES. 
internacional han formulado para Colombia, sus implicaciones y efectos a partir de las principales problemáticas que subyacen al sistema. Todo esto con el fin de resaltar la necesidad de realizar adecuaciones legislativas que permitan reformar estructuralmente el sistema pensional, para tal fin se acogen las propuestas de uno u otro organismo que mejor se adapten a las problemáticas del sistema pensional colombiano.

\section{Palabras clave:}

Seguridad social, Sistema pensional, Reforma pensional, Sostenibilidad financiera, Organismos económicos.

\section{Abstract}

Currently, the Colombian pension system is facing a serious crisis associated with various factors, among which are the sustainability of the system, population aging, low coverage rates, and others. Nevertheless, it is possible to point out that this crisis dates back to the origins of the system, where the lack of foresight in the adoption of a sustainable model and the structural failures of the system generated, over time, difficulties that threaten its existence. Given this situation, initiatives that aim to cope with this crisis have emerged from different political and economic sectors and organizations. However, these proposals imply serious reforms to the current scheme and face some legal limitations. Therefore, the present paper analyses, through a documental tracking, the reform proposals to the general pension system that different international economic organizations have formulated for Colombia, their effects and implications based on the main issues underlying the system. All of this in order to highlight the need to accomplish legislative adjustments that allow for a structural reform of the pension system. To that end, proposals made by different organizations that best adapt to the challenges of the Colombian pension system are acknowledged.

\section{Keywords:}

Social security; pension system; pension system reform; financial sustainability; economic organizations.

\section{Cómo citar este artículo:}

Mejía, J. (2020). sistema pensional en Colombia y organismos económicos multilaterales: algunas perspectivas de reforma. Revista de la Facultad de Derecho y Ciencias Políticas, 50 (132), pp. 29-49. doi: http://dx.doi.org/10.18566/rfdcp.v50n132.a02

Recibido: 28 de abril de 2019.

Aprobado: 13 de agosto de 2019. 
Hoy en día la seguridad social es acaso lo más inseguro que existe, y las pensiones son una especie en franca extinción ante la notoria decadencia

del Estado de bienestar que las inventó. Ángel Guillermo Ruíz Moreno

\section{Contexto del sistema pensional colombiano}

Los orígenes del sistema pensional en Colombia se remontan a los años cuarenta con la creación de la Caja Nacional de Previsión (CAJANAL) y el Instituto Colombiano de Seguros Sociales (ICSS), primeras entidades que conformarían el naciente sistema de seguro social (Arrieta Mendoza, 2011). Con la expedición de la ley $6^{\text {ta }}$ de 1945 (ley 6, 1945), se generalizaron los derechos a pensión, salud y riesgos profesionales de los trabajadores. La obligación de los empleadores era entonces asumir el pago de la pensión de aquellos trabajadores que alcanzaran la edad de retiro — que para esta época ascendía a cincuenta años de edad - y acumularan veinte años de servicios cotizados de manera continua o discontinua.

Posteriormente, con la expedición de la ley 90 de 1946 (ley 90, 1946), se estableció un sistema de seguro social donde se reconocían pensiones de jubilación, primas no salariales y ayudas relacionadas con la prestación de servicios de salud, promovidas con la creación del ICSS, entidad con personería jurídica y patrimonio autónomo cuya función era la de dirigir y vigilar los seguros sociales. Bajo estas normativas, todos los individuos, nacionales y extranjeros, que prestaran sus servicios a otra persona en virtud de un contrato de trabajo expreso o presunto, incluyendo a los trabajadores a domicilio y los del servicio doméstico, ostentaban la condición de asegurados por el régimen del seguro social obligatorio.

Los recursos del sistema necesarios para cubrir las prestaciones económicas y en especie provenían de una fuente tripartita, basada en un esquema de triple contribución forzosa, conformada por los asegurados, los patronos y el Estado.

Con respecto a la protección de la vejez, hasta esa fecha en Colombia se presentaban serias deficiencias estructurales que tornaban al modelo vigente inequitativo y poco viable financieramente (Santa María, Steiner, Botero, Martínez, \& Millán, 2010). En consecuencia, las excesivas prestaciones 
reconocidas por el sistema, la ambigüedad en su consagración, la falta de planeación de su financiación y sostenibilidad, entre muchos otros; se constituyeron en factores determinantes en la inequidad e inviabilidad financiera del sistema.

A esto se sumó que la organización financiera de los seguros de vejez, invalidez y muerte adoleció de un grave problema de imprevisión, cuya responsabilidad en igual medida recaía sobre el gobierno, los empresarios y los trabajadores. El gobierno incumplió con las transferencias que estaba obligado a aportar; además, omitió reajustar las cotizaciones y obligaciones con el sistema y, en cambio, el sistema otorgó beneficios pensionales exorbitantes sin ningún tipo de compensación al sistema (Castaño, 1992).

La crisis del sistema derivó en la necesidad de implementar reformas de carácter estructural que aliviaran el grave problema de cobertura y financiación. Este fenómeno coincidió con el auge de un nuevo modelo constitucional que propugnaba por un carácter fundamental y universal de la seguridad social.

\section{La Constitución de 1991 y la aparición del Sistema Integral de Seguridad Social}

Dentro de las propuestas analizadas por la Asamblea Nacional Constituyente, en específico, por la Comisión Accidental sobre Seguridad Social y Salud (1991), la finalidad social del Estado se centraba en procurar el bienestar general y el mejoramiento de la calidad de vida de la población atendiendo a los principios de universalidad, continuidad y solidaridad.

De este modo, entre las propuestas se contempló la seguridad social como un derecho irrenunciable de la persona humana, consubstancial a la naturaleza humana y de obligatorio cumplimiento. Este debía estar en cabeza de todos los habitantes, durante todas las etapas de su existencia, especialmente, en las de la infancia y la vejez.

Como obligados a garantizar dichas prerrogativas, dentro de las propuestas esbozadas por la Asamblea Nacional Constituyente se consideró al Estado en concurrencia con los particulares y las entidades territoriales. Otras incluso, consideraron que la seguridad social estaría a cargo del Estado, de los empresarios, los usuarios y la comunidad social: "en un concurso distributivo 
y con aplicación de la cooperación internacional”. (Asamblea Nacional Constituyente, 1991, p.3).

De acuerdo con la concepción universalista de la seguridad social, se contempló entre las propuestas que la seguridad social incluyera el cuidado de la salud, la enfermedad, maternidad, enfermedad profesional, accidentes de trabajo e invalidez, vejez y muerte. Esto se ampliaría de manera progresiva hasta incluir la prestación de otros servicios. Se propuso, entonces, la financiación del sistema a través de aportes de la nación, las entidades territoriales y los particulares, sumado a las contribuciones de los empleadores y trabajadores, con la posibilidad de otorgar subsidios para promover el acceso.

Conforme a los nuevos lineamientos constitucionales, se dio inicio a las discusiones legislativas, a fin de implementar un nuevo sistema de seguridad social que respondiera al nuevo esquema constitucional. Fue así como en la exposición de motivos de lo que sería posteriormente la ley 100 de 1993 (ley 100, 1993), se señalaba que el gobierno de la época había diseñado un ambicioso proyecto que otorgaba en materia pensional, alternativas diferentes a los trabajadores, a fin de garantizar el pago oportuno y cierto de las pensiones (Congreso de la República de Colombia, s. f., p.1).

De igual forma, se mencionó que, junto a la implementación de un modelo de pensiones, se presentaría un proyecto complementario en el régimen de salud, donde la decisión del trabajador sería primordial, así como los principios de eficiencia, solidaridad y universalidad.

Con todo, se pretendía dar comienzo a una reforma de seguridad social que se adecuara a los nuevos mandatos constitucionales y al creciente desarrollo económico, según tres ejes centrales:

1. La creación de un nuevo sistema pensional basado en el ahorro y la capitalización individual a partir de las contribuciones hechas por trabajadores y empleadores. El sistema pensional sería complementado por seguros que permitieran amparar los riesgos de la invalidez y la sobrevivencia. Se pretendía, entonces, garantizar pensiones básicas a través de garantías estatales, con el fin de proteger los ahorros y sustentar una rentabilidad mínima.

2. A fin de garantizar los derechos adquiridos de quienes ya se habían pensionado, se implementaría una reforma en el financiamiento del ISS con modificaciones graduales, que hicieran frente a los cambios demográficos 
que afectaban el sistema, eliminando a su vez los excesos en los beneficios concedidos.

La generación de deuda del sistema pensional se frenaría elevando las cotizaciones al nivel de costo de largo plazo de las prestaciones. Igualmente, por razones de equidad y para evitar discriminaciones en el mercado laboral, las cotizaciones y la distribución de estas entre trabajadores y empleadores serían igualadas.

3. Por último, se daría paso a un proceso de expansión de la protección pensional a la tercera edad a la que no le fue posible acceder a los sistemas pensionales contributivos. Esto a partir de la creación de auxilios monetarios para los pobres.

Lo anterior implicaría el surgimiento de un esquema pensional de corte privado, basado en el ahorro individual y diferente al esquema vigente hasta aquella época.

El nuevo sistema sería aplicado de manera automática para los nuevos trabajadores que ingresaran a la fuerza laboral. A largo plazo, este reemplazaría el sistema pensional vigente. Con todo, la permanencia o traslado de los afiliados dependían expresamente de su decisión individual. De ahí que, las entidades integrantes del sistema propugnarían por prestar un mejor servicio y mejores rentabilidades a fin de captar afiliados en un esquema de competencia.

De los tres ejes centrales de la propuesta inicial planteada por el gobierno, se evidenciaba una necesidad imperante de hacer frente al alto gasto presupuestal debido al sistema pensional vigente. Para esto se daría paso a un sistema individual, donde el aporte del individuo se constituyera en la principal fuente de financiación.

El papel del Estado se limitaba a regular el funcionamiento del sistema y a asegurar el cumplimiento de los beneficios pasados y futuros; mientras que a los individuos correspondía financiar el acceso a esos beneficios con sus aportes. Todo esto con una reducción paulatina de las obligaciones del empleador.

La inviabilidad financiera del sistema vigente, el alto impacto económico, la inequidad, la falta de expansión y crecimiento de la cobertura se constituían en las principales razones para la implementación de un régimen enteramente distinto, a saber, un esquema de capitalización individual. Sin embargo, este 
conservaba ciertas garantías y componentes solidarios, a saber, la garantía estatal para acceder a pensiones y rentabilidades mínimas, la protección de las cuentas de ahorros al asegurar el pago de las rentas en caso de incumplimiento de las administradoras y aseguradoras, así como la garantía de pensiones mínimas en caso de que el afiliado no contara con el capital necesario.

Empero, aunque inicialmente la propuesta se inclinó hacia un esquema de capitalización donde el acceso a beneficios dependiera en su mayoría de los ahorros del afiliado; el legislador optó por la implementación de un esquema paralelo, donde el antiguo esquema de carácter público coexistía en competencia con un esquema de capitalización individual con enfoque privado.

Con respecto a la previsión de la vejez, la ley 100 de 1993 (ley 100, 1993) dio origen a dos regímenes complementarios pero diferentes con que se podría acceder a un aseguramiento para la vejez. El primero de ellos, el Régimen de Prima Media con prestación definida (RPM), administrado por una entidad de carácter público, establece condiciones generales para el acceso a derechos pensionales (edad y semanas) y el pago de los mismos dependen de los aportes de los afiliados y la contribución del Estado. Por otro lado, el Régimen de Ahorro Individual con Solidaridad (RAIS), administrado por entidades de carácter privado, establece condiciones específicas para el acceso a las pensiones de vejez, pues las mismas dependen exclusivamente de los aportes del afiliado y de la rentabilidad que los mismos hayan producido.

A pesar de que se estableció el carácter complementario de ambos regímenes, desde sus inicios en 1993 ha sido notoria una disparidad en la sostenibilidad de ambos regímenes, pues las grandes reformas han recaído en su mayoría sobre el RPM, el régimen que mayores problemas presenta en la actualidad, debido a la falta de equidad en la distribución de subsidios y beneficios que se otorgan. Además, su financiamiento depende principalmente de las contribuciones de los afiliados, situación agravada por la alta informalidad laboral y los cambios demográficos. Por tal motivo, hoy en día se habla de una necesidad de reforma estructural del sistema general de pensiones, donde se dé solución a los problemas de sostenibilidad que afectan principalmente al RPM.

La adopción de un esquema competitivo, la falta de reformas estructurales y el elevado costo presupuestal del régimen de reparto simple, conllevaron a que se implementaran reformas paramétricas que hicieran frente a la crisis del sistema. 
Normativamente, la necesidad de reformar el sistema se hizo manifiesta con la implementación de las leyes 797 y 860 del 2003 (ley 797 y 860, 2003) y el Acto Legislativo 01 de 2005, que marcaron el inicio del aumento gradual en los requisitos para acceder a las prestaciones económicas para la vejez, así como la aparición de nuevas modalidades que intentaran ampliar la cobertura, la equidad y la sostenibilidad del sistema a través de beneficios económicos periódicos.

No obstante, los cambios normativos introducidos desde la entrada en vigencia del sistema se han mostrado insuficientes para hacer frente a la crisis. Esto ocasionó la aparición de múltiples propuestas de reforma, entre ellas, las emanadas de organismos económicos de carácter multilateral.

\section{Organismos económicos multilaterales y su papel en los procesos de reforma}

El papel de las entidades económicas objeto de estudio en los procesos de reforma legislativa en el mundo se evidencia en los lineamientos jurídicos que dichas entidades establecen a aquellos Estados que pretenden acceder a algún tipo de préstamo o inversión. De allí proviene la fuerza vinculante de las directrices emanadas de estos organismos y de su poder de influencia en la agenda legislativa de los Estados.

Para estas entidades: "la necesidad de reformas de los marcos legales en los países en vías de desarrollo aparece como condición central para el éxito del modelo económico orientado por el mercado” (Burgos, 2000, p. 47). De igual forma, ha habido un interés particular de diversos organismos por desarrollar instituciones jurídicas vinculadas con el desarrollo económico y social de los países, pues el funcionamiento errático de la administración de justicia genera costos y riesgos indeseables para la inversión internacional, fundamental para el crecimiento económico de los estados (Burgos, 1999, p.191).

A propósito del sistema de seguridad social, elementos como la sostenibilidad financiera, la cobertura y al acceso a los beneficios concedidos por el sistema han estado en el la mira de diversos organismos, cuyo papel ha sido primordial en las olas de reforma pensional que se han dado en América Latina. 
La primera generación de reforma pensional en América Latina se origina, según la Organización para la Cooperación y el Desarrollo Económico (en adelante $\mathrm{OCDE}^{2}$ ), en Chile en 1981, debido al paso de un esquema público financiado bajo un modelo de financiación pay-as-you-go a un esquema privado, bajo un modelo de capitalización individual. Además de señalar a América Latina como un laboratorio de reforma pensional, la OCDE resalta la importancia del caso chileno como el inicio de una ola reformista en los sistemas pensionales en la región, pues después de este país, siete países latinoamericanos decidieron reformar sus sistemas de pensiones de acuerdo con la experiencia chilena (Queisser, 1997).

Posteriormente, se dio inicio a una "segunda generación" de reformas, que se llevaron a cabo en Perú en 1993, seguido de Colombia y Argentina en 1994, México en 1995, Uruguay en 1996, Bolivia en 1997 y El Salvador en 1998. Como ya se señaló, aunque en principio en Colombia se pretendió replicar en gran medida la experiencia chilena, finalmente se optó por acoger un sistema paralelo, donde el esquema público y privado coexistían en franca competencia. Por esta razón no es posible determinar el éxito de un esquema de capitalización individual en el país. Dada la subsistencia de un esquema de reparto simple, ha resurgido, por parte de estos organismos, un interés de reformar el sistema, debido a las crisis que atraviesa el esquema de reparto producto de los cambios demográficos, económicos, sociales y culturales de las sociedades actuales.

\section{BID, OCDE Y Banco Mundial: Perspectivas de reforma para Colombia}

A continuación, se expondrán las perspectivas de reforma pensional en Colombia propuestas por tres de los principales organismos económicos multilaterales que se han pronunciado sobre la materia: el BID, la OCDE y el Banco Mundial.

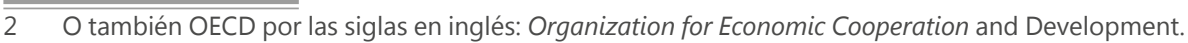




\section{- Banco Interamericano de Desarrollo (BID)}

En palabras de la misma entidad, el BID se denomina como la principal fuente de financiamiento y pericia multilateral para el desarrollo económico, social e institucional sostenible de América Latina y el Caribe (Banco Interamericano de Desarrollo, 2019.). Aunque los lineamientos y recomendaciones de la entidad versan sobre diferentes asuntos, su propuesta de reforma pensional para Colombia se centra en cinco ejes centrales: 1 . la falta de cobertura, 2 . la inequidad del sistema, 3 . la competencia entre regímenes, 4 . la sostenibilidad fiscal producto de la transición demográfica y 5 . la informalidad laboral.

Para afrontar la falta de cobertura, el BID propone la expansión de programas como Colombia Mayor y los Beneficios Económicos Periódicos BEPS, que se han instituido como alternativas sustitutas del esquema pensional, a las que se accede ante la imposibilidad de obtener una pensión de vejez en alguno de los dos regímenes. El BID centra su propuesta de reforma en la implementación de un sistema contributivo único integrado, complementado con un pilar básico no contributivo que amplíe la cobertura a corto plazo (Bosch, Berstein, Castellani, Oliveri y Villa, 2015). Esto implica la reforma del régimen de prima media 0 , en su defecto, su marchitamiento hasta convertirlo en un pilar básico de beneficios definidos (Bosch et al., 2015).

La adopción de un esquema contributivo único podría tener consecuencias positivas sobre el sistema dado que, al tratarse de un esquema único, se elimina la competencia entre regímenes. Situación que incide de manera negativa en la sostenibilidad de aquellos esquemas de financiación que dependen en gran medida del aporte de los afiliados. Por otro lado, la adopción de este esquema podría aparejar un incremento gradual de la cobertura, a verificar en la cantidad de afiliados y personas que acceden a los beneficios concedidos por el sistema.

Por otro lado, la adopción de un sistema único implica que las prestaciones económicas concedidas han de ser unificadas en igual medida. Situación que podría solucionar los problemas de inequidad presentes en el esquema actual de reparto simple.

Sin embargo, el marchitamiento del RPM genera incertidumbre acerca de los derechos de aquellos afiliados que hacen parte actualmente de este esquema. Al respecto, hay que aclarar que el marchitamiento propuesto se daría de manera gradual, bajo la adopción de prerrogativas o disposiciones 
que mantuvieran el derecho de determinados afiliados, bajo la adopción de un régimen de transición.

Con todo, la entidad plantea la necesidad de mejorar el funcionamiento de las administradoras de pensiones que conforman el RAIS, a fin de aumentar su competitividad, inversiones y supervisión a través de varias estrategias: la primera es permitir la participación de otros intermediarios financieros en la gestión de los recursos producto del ahorro para la jubilación. La segunda estrategia es ofrecer mayor libertad al afiliado para elegir entre la variedad de productos financieros ofrecidos por el sistema. La tercera estrategia es permitir la flexibilización de las inversiones que realizan las administradoras, permitiendo el libre acceso en mercados de inversiones extranjeros (Blommestein, 1997).

Bajo el esquema adoptado en el RAIS, resulta positivo permitir la inversión de los recursos de cada afiliado y según sus condiciones individuales, a consideración de la administradora. Debido a que es la entidad quien está en mejor capacidad de tomar dicha decisión. Sin embargo, no se comparte la apreciación realizada por el BID, al considerar que las garantías de rentabilidad mínima son un elemento negativo en cuanto limita el acceso al mercado, al limitar la competencia en el negocio de las $\mathrm{AFP}^{3}$ (Blommestein, 1997). Esto debido a que podría resultar negativo para el afiliado que no se le garantice una rentabilidad o beneficio mínimo, elemento contrario a un enfoque solidario que permea al sistema.

Sin embargo, debe reconocerse que lo planteado por la entidad responde a las lógicas propias de un esquema de capitalización individual, por lo que podría trasladarse al Estado la obligación de garantizar el acceso a beneficios mínimos para la vejez, en caso de rentabilidades negativas o crisis de mercado.

Hasta este punto es posible advertir que al BID le asiste un interés particular en fortalecer un esquema de capitalización individual, con la reducción de la participación del esquema público a programas de asistencia y solidaridad. Esta propuesta en sí misma no resulta novedosa, pues como se mencionó, fueron diversas las reformas que en América Latina intentaron acogerla. En Colombia esto sucedió en 1991, sin que tal intención se materializara en su

3 En el texto original se dice: "Minimum profitability guarantees and minimum capital rules (they can be used to restrict market access, thereby limiting competition in the pension fund management business) may also need to be reviewed". (Blommestein, 1997, p. 21) 
totalidad, pues se optó por la subsistencia de un régimen de reparto simple de naturaleza pública.

Ante la idea de transitar hacia un esquema de capitalización individual con un enfoque privado, resulta pertinente retomar las experiencias regionales, que permiten evidenciar el desencanto por estas propuestas, hasta el resurgimiento de esquemas de reparto con un alto enfoque solidario.

Como bien lo reseña Morales (2015), entre las razones que moderaron el entusiasmo por la privatización de los sistemas de pensiones se encuentran: el incumplimiento de las bondades del sistema, las evaluaciones realizadas a los países de la región y los cambios de postura de las instituciones financieras internacionales promotoras del sistema y la crisis del 2008-2009. De igual forma, el paradigma de la gestión del riesgo social se topó con obstáculos como la alta informalidad, el desempleo y los bajos salarios.

El panorama colombiano es similar al descrito por la autora, por esto se considera que las propuestas tendientes a la privatización exclusiva del sistema o la preponderancia de un esquema de capitalización individual deben ser adoptadas con prudencia, de acuerdo con las experiencias de los demás países de la región.

Quizá una de las propuestas de mayor controversia planteada por la entidad se relaciona con el monto de las pensiones reconocidas por el sistema y su relación con el salario mínimo. Sobre el tema, la entidad señala que el nivel y ajuste de la pensión mínima debería ser revisado. En otras palabras, el hecho de que en el país ninguna pensión pueda ser inferior al salario mínimo, como lo dispuso el Acto Legislativo 01 del 2005 y, a su vez, que dicho valor esté sujeto a elementos políticos, hacen que el aseguramiento y el otorgamiento de beneficios resulte complejo.

En el caso del RPM, esta complejidad reside en la altos costo de los beneficios otorgados; mientras que, en el RAIS, la relación pensión-salario mínimo impacta en el precio del seguro previsional, las rentas vitalicias y la manera en la que el retiro programado funciona (Bosch et al., 2015).

En síntesis, se presentan tres opciones para hacer frente a esta situación: La primera, desligar la figura de pensión mínima del salario mínimo, al eliminar las restricciones que pone al sistema el salario mínimo, es desligar la pensión mínima de salario mínimo, que permita el ajuste de aquella por inflación. 
Segunda opción, se propone ajustar del salario mínimo por la inflación. Según la entidad, esto tendría el beneficio añadido de facilitar la creación de trabajo formal. Por último, se propone una desconexión entre la pensión mínima y el salario mínimo, a través de generación de salarios mínimos por profesiones o regiones.

Si bien existe prohibición constitucional al respecto, se comparte el planteamiento de la entidad, en cuanto resulta necesario desligar el monto de las mesadas pensionales con el salario mínimo. En primer lugar, bajo un enfoque integral del sistema de seguridad social, es deber del Estado propugnar por el acceso efectivo de la población durante la vejez a servicios fundamentales, como la salud, y complementarios, como en otros casos.

De ser así, los gastos del individuo durante la etapa de desacumulación han de ser inferiores a aquellos durante su etapa productiva, por esto, en algunos casos, sería admisible que el ingreso durante la vejez no dependiera necesariamente del salario mínimo.

Consecuentemente, desligar la pensión mínima del salario mínimo tendría una incidencia directa sobre la cobertura del sistema y el acceso a beneficios en el mismo, pues al relajarse esta limitante, el número de personas que acceden a prestaciones económicas al interior del sistema aumentaría. Por tanto, resulta necesario complementar esta medida con el acceso a otros derechos por parte del sistema de seguridad social, que permita al individuo mantener su calidad de vida.

Para la implementación de esta propuesta se requiere entonces de una reforma constitucional que elimine la restricción introducida en el artículo 48 de la Constitución a través del Acto Legislativo 01 de 2005. No obstante, la misma disposición permitió el reconocimiento de beneficios, sin que para esto aplique la restricción enunciada, todo esto a través de beneficios económicos periódicos o BEPS.

Es necesario aclarar que los BEPS no son una modalidad pensional, en cuanto su regulación y reconocimiento difiere sustancialmente de las modalidades pensionales vigentes en el sistema. Por tanto, a pesar de que exista esta modalidad, la misma no debe ser vista como una evasión a la restricción constitucional; sino que se trata de un beneficio integrante del sistema, cuyo objetivo primordial es aumentar su cobertura. 
Por lo demás, la entidad propone reformas paramétricas al sistema, flexibilización en el modelo de recaudo y demás, que serán resumidas posteriormente en la tabla titulada síntesis de lineamientos de reforma pensional para Colombia.

\section{- Organización para la Cooperación y el Desarrollo Económico (OCDE)}

Al reconocer la desigualdad como uno de los principales problemas en Colombia, la OCDE asocia la crisis del sistema pensional colombiano y la pobreza durante la vejez al elevado nivel de informalidad laboral. Sin embargo, para la Organización resulta preocupante el reducido nivel de cobertura del sistema. Según este organismo, esta solo cubre a los empleados del sector formal cuyos ingresos son superiores al salario mínimo, que es relativamente alto.

Para la OCDE, el salario mínimo tiene una incidencia importante en la crisis que actualmente atraviesa el sistema, pues el vínculo entre las prestaciones y el salario mínimo hacen que el sistema sea costoso. Esta situación afecta en igual medida a las entidades del sector privado, quienes reducen la provisión de rentas vitalicias dadas las dificultades de asegurarse frente a los futuros cambios del salario mínimo (OECD, 2015).

La imprevisibilidad del salario mínimo y el alto costo que genera la imposibilidad de reconocer pensiones por debajo de este monto, justifican unas de las principales propuestas de este organismo, a saber, que se permita el reconocimiento de pensiones inferiores al salario mínimo, en concordancia con la reducción a la mitad de la tasa de reemplazo del sistema público para acercarla al régimen privado.

Para la entidad, la reducción de la tasa de reemplazo del sistema público ayudaría a eliminar la competencia entre regímenes, al reducir a la vez los subsidios a los altos subsidios concedidos a los más adinerados en el régimen de prima media. Razón tiene la entidad al reseñar los altos subsidios concedidos a los más adinerados como un problema del sistema, pues es evidente que los excesivos beneficios otorgados por el RPM a aquellos cotizantes que devengan altos salarios constituyen una fuente de inequidad del sistema. Así las cosas, la reducción en la tasa de reemplazo reduciría en gran medida la amplia brecha de desigualdad entre quienes devengan altos salarios y aquellos cuyos 
ingresos sólo alcanzan el salario mínimo. Esto tendría un efecto positivo sobre la sostenibilidad del sistema, al reducir el costo de los subsidios pagados a las personas con los salarios más altos.

Por otro lado, junto a otras reformas paramétricas (aumento y equiparación de la edad, tiempo para el cálculo del IBL, entre otros.), a largo plazo el organismo recomienda realizar una reforma integral cuyo eje central sea un Plan privado de contribuciones definidas a complementar con un plan público básico que se sugiere retirar gradualmente mediante el pago de un "bono pensional" por fuera de la regla fiscal (Chaparro, 2015).

Para la OCDE, la introducción de programas alternativos como los BEPS resulta beneficioso para el sistema, pues a través de ellos se logra un aumento sustancial de la cobertura. En tal medida, se propone ampliar los requisitos de elegibilidad para acceder a estos programas, así como su fortalecimiento a través de una mayor subvención estatal.

\section{- Banco Mundial (BM)}

La propuesta del BM dista un poco de aquellas formuladas por los dos organismos anteriores, pues más allá de desmontar uno u otro régimen, plantea implementar una reforma pensional basada en pilares, cada uno de ellos con un objetivo, sector poblacional y esquema de financiación diferente. Como señala Mesa-Lago (1996), los tres pilares difieren en cuanto a su naturaleza legal, régimen financiero, contribuciones, beneficios y administración.

Por consiguiente, se propone: i) un primer pilar obligatorio, financiado con impuestos y con objetivos de redistribución. En este pilar se garantiza un beneficio mínimo o uniforme, todo ello administrado por el sector público. ii) Un segundo pilar que también es de carácter obligatorio, cuyos objetivos son el ahorro y el seguro, con beneficios no definidos y contribuciones definidas, a través de un plan de ahorro individual en el que sólo contribuye el asegurado, 0 un plan de ahorro del empleador o la empresa en el que contribuyen el asegurado y el empleador, administrado por el sector privado pero regulado por el Estado. iii) Un tercer pilar voluntario, similar al segundo pilar en cuanto tiene como objetivo el ahorro, pero sin beneficios ni contribuciones definidas (Banco Mundial, 1994). La propuesta del BM pretende hacer frente a la falta de financiación que podría generar un pilar único, sumado a las distorsiones del mercado laboral, la falta de cobertura y la evasión. 
La propuesta del BM resulta atractiva si se tiene en cuenta el modelo actual del esquema pensional colombiano, pues es posible afirmar que en el esquema actual ya se encuentran construidos los cimientos para edificar la propuesta planteada por el organismo. Por tanto, el pilar obligatorio, financiado con impuestos y con objetivos de redistribución, estaría a cargo del RPM. Actualmente este se financia con el presupuesto público, debido al agotamiento de las reservas o fondo común con el que debería contar este régimen. El beneficio mínimo uniforme del que habla la entidad no debe ser necesariamente un equivalente al salario mínimo, lo que podría coincidir con las propuestas de los demás organismos. La administración del pilar, a cargo del sector público, le correspondería a Colpensiones, tal como funciona en la actualidad.

El segundo pilar podría estar a cargos de las AFP que administran el RAIS. Según la propuesta, por tratarse de un plan de ahorro individual, este acogería las lógicas del esquema de capitalización actualmente vigentes. Por último, el tercer pilar voluntario podría ser manejado por las mismas AFP, como sucede en la actualidad con los planes de pensiones voluntarias.

La propuesta del BM, de ser implementada en Colombia, consistiría básicamente en dotar de un carácter complementario al sistema general de pensiones, lo que daría solución al problema de competencia que actualmente se presenta entre regímenes. La implementación de un esquema de pilares podría contribuir a solucionar el grave problema de sostenibilidad financiera del RPM, si la afiliación al primer pilar se torna obligatoria, pues se contaría con un mayor número de afiliados que contribuyan con el ingreso de recursos al sistema.

No obstante, se considera que por sí sola esta no es una solución, pues se requiere que simultáneamente se generen mecanismos que incentiven el aporte, faciliten la cotización y garanticen no solo el acceso a beneficios; sino al mismo sistema, a través de la flexibilización del aporte o la implementación de mecanismos alternativos de cotización como lo plantea el BID (Bosch et al., 2015).

Por otro lado, es claro que la propuesta planteada por el BM evitaría el impacto social negativo que implica el marchitamiento del RPM, así como el riesgo jurídico subyacente al desmonte de dicho régimen a propósito de los derechos de los afiliados. 
Sin embargo, la subsistencia del RPM o de un esquema de carácter público dentro del sistema mantiene viva las problemáticas propias de aquellos esquemas basados en la solidaridad intergeneracional y las relaciones de trabajo formales. Esto no significa que la solución debe ser el desmonte de los esquemas solidarios, de reparto o de carácter público ni tampoco la defensa de los esquemas de capitalización individual, pues como ya se dijo, tales propuestas deben ser contrastadas con las experiencias de países vecinos. Sólo se pretende hacer énfasis en la necesidad de que esquemas de financiación estructurados en otros tiempos sean necesariamente revaluados, pues está claro que las condiciones demográficas, laborales, sociales, económicas y culturales no son las mismas.

Tabla 1: Síntesis de lineamientos de reforma pensional para Colombia.

\begin{tabular}{|l|l|l|l|}
\hline & BID & OCDE & BM \\
\hline EJES DE REFORMA & $\begin{array}{l}\text { Cobertura, inequi- } \\
\text { dad, competencia } \\
\text { entre regímenes, } \\
\text { sostenibilidad } \\
\text { fiscal, transición } \\
\text { demográfica e } \\
\text { informalidad } \\
\text { laboral. }\end{array}$ & $\begin{array}{l}\text { Cobertura, soste- } \\
\text { nibilidad, equidad } \\
\text { formalización } \\
\text { laboral. }\end{array}$ & $\begin{array}{l}\text { Cobertura, suficien- } \\
\text { cia y sostenibilidad. }\end{array}$ \\
\hline ESTRUCTURA DEL \\
SISTEMA & $\begin{array}{l}\text { Sistema contribu- } \\
\text { tivo único integra- } \\
\text { do, marchitamien- } \\
\text { to de régimen de } \\
\text { prima media o su } \\
\text { reforma estruc- } \\
\text { tural. Expansión } \\
\text { de programas de } \\
\text { asistencia. }\end{array}$ & $\begin{array}{l}\text { Fortalecimiento del } \\
\text { esquema privado, } \\
\text { con posibilidad de } \\
\text { desmonte gradual } \\
\text { del plan público } \\
\text { básico. Amplia- } \\
\text { ción de los BEPS y } \\
\text { Colombia Mayor. }\end{array}$ & $\begin{array}{l}\text { Sistema de pilares. } \\
\text { Integración entre } \\
\text { pensiones contribu- } \\
\text { tivas y no contributi- } \\
\text { vas. Administración } \\
\text { privada. }\end{array}$ \\
\hline ESOUEMA DE FI- & $\begin{array}{l}\text { Principalmente } \\
\text { individual, o en su } \\
\text { defecto, de forma } \\
\text { complementaria } \\
\text { entre asistencia y } \\
\text { aportes individua- } \\
\text { les. }\end{array}$ & $\begin{array}{l}\text { Principalmente in- } \\
\text { dividual, amplian- } \\
\text { do la cobertura y } \\
\text { la equidad de los } \\
\text { programas de sub- } \\
\text { sidios a la tercera } \\
\text { edad. }\end{array}$ & $\begin{array}{l}\text { Dependiendo de cada } \\
\text { pilar: impuestos } \\
\text { generales y contribu- } \\
\text { ciones individuales. }\end{array}$ \\
\hline
\end{tabular}




\begin{tabular}{|c|c|c|c|}
\hline & BID & OCDE & BM \\
\hline $\begin{array}{l}\text { REFORMAS AL RE- } \\
\text { CAUDO O APOR'TES }\end{array}$ & $\begin{array}{l}\text { Flexibilización del } \\
\text { recaudo a través } \\
\text { de mecanismos } \\
\text { alternativos de } \\
\text { cotización, como } \\
\text { facturas de ser- } \\
\text { vicios públicos y } \\
\text { similares. }\end{array}$ & $\begin{array}{l}\text { Subvención de } \\
\text { contribuciones a } \\
\text { través de progra- } \\
\text { mas de beneficios } \\
\text { al adulto mayor. }\end{array}$ & $\begin{array}{l}\text { Dependiendo de las } \\
\text { capacidades de cada } \\
\text { individuo. Se propo- } \\
\text { ne potenciar esque- } \\
\text { mas de subsidios. }\end{array}$ \\
\hline $\begin{array}{l}\text { REFORMAS PARA- } \\
\text { MÉTRICAS }\end{array}$ & $\begin{array}{l}\text { Igualar edades } \\
\text { para acceder } \\
\text { a pensión de } \\
\text { vejez: } 62 \text { años } \\
\text { para hombres y } \\
\text { mujeres. Cálculo } \\
\text { del IBL con los } \\
\text { últimos } 20 \text { años. } \\
\text { Impuesto del 10\% } \\
\text { a ciertas pensio- } \\
\text { nes. }\end{array}$ & $\begin{array}{l}\text { Salario mínimo } \\
\text { diferenciado. } \\
\text { Impuesto sobre las } \\
\text { pensiones altas. } \\
\text { Reducción a la } \\
\text { mitad de la tasa de } \\
\text { reemplazo. Incre- } \\
\text { mento en los años } \\
\text { para el cálculo del } \\
\text { IBL. Incremento } \\
\text { gradual conforme } \\
\text { a la esperanza de } \\
\text { vida y equiparación } \\
\text { de la edad de pen- } \\
\text { sión para hombres } \\
\text { y mujeres. } \\
\end{array}$ & $\begin{array}{l}\text { Aumento gradual de } \\
\text { la edad. Aumento } \\
\text { del tiempo para el } \\
\text { cálculo del ingreso } \\
\text { pensional. }\end{array}$ \\
\hline $\begin{array}{l}\text { REFORMAS EXÓGE- } \\
\text { NAS AL SISTEMA }\end{array}$ & & $\begin{array}{l}\text { Reducción de los } \\
\text { costos no salaria- } \\
\text { les, flexibilización } \\
\text { laboral. Educación } \\
\text { financiera relacio- } \\
\text { nada con las pen- } \\
\text { siones privadas. } \\
\end{array}$ & \\
\hline $\begin{array}{l}\text { BENEFICIOS O'TOR- } \\
\text { GADOS }\end{array}$ & $\begin{array}{l}\text { Pensiones infe- } \\
\text { riores al salario } \\
\text { mínimo. Subsidios } \\
\text { y beneficios asis- } \\
\text { tenciales alterna- } \\
\text { tivos. }\end{array}$ & $\begin{array}{l}\text { Pensiones infe- } \\
\text { riores al salario } \\
\text { mínimo. }\end{array}$ & $\begin{array}{l}\text { Pensiones equivalen- } \\
\text { tes al } 50 \% \text { del salario } \\
\text { medio bruto recibido } \\
\text { durante todos los } \\
\text { años de trabajo. } \\
\text { Límite mínimo equi- } \\
\text { valente a la línea de } \\
\text { pobreza. }\end{array}$ \\
\hline
\end{tabular}

Fuente: Elaboración propia. 


\section{Conclusiones}

Las propuestas analizadas tienen varios elementos en común, entre ellos, los ejes centrales de reforma, así como las problemáticas señaladas como justificativas de las propuestas. La baja cobertura del sistema y la sostenibilidad son el fundamento en las propuestas de los tres organismos. Por otro lado, todos coinciden en un elemento: la necesidad de modificar los beneficios otorgados por el sistema, así como eliminar la barrera del salario mínimo, que impide el otorgamiento de beneficios pensionales inferiores al salario mínimo.

Las propuestas de reforma que versan sobre requisitos para acceder a beneficios (reformas paramétricas), así como el esquema de financiación a adoptar, requieren de reformas legislativas, ya que la consagración de estos elementos se encuentra en leyes de carácter ordinario y bastaría con la adopción de disposiciones normativas posteriores que los modifiquen. Todo esto sin desconocer el alto impacto social y político que dichas reformas conllevan, por tratarse de modificaciones legislativas impopulares.

Sin embargo, las reformas relacionadas con los beneficios otorgados por el sistema, así como la forma en que estos se calculan resulta más compleja, a partir de sus implicaciones en los derechos otorgados por el sistema y las limitantes establecidas por el artículo 48 de la Constitución Política (Const., 1991, art. 48) y el Acto Legislativo 01 del 2005.

Se considera que la adopción de esquemas o propuestas de reforma pura o estrictas deben ser descartados de plano, dado que las lógicas propias del asunto impiden que un modelo pueda ser desarrollado a plenitud. Al respecto, se comparte lo planteado por Mesa-Lago (1996) cuando afirma que los partidarios de uno y otro modelo (reparto simple y capitalización individual) han oscurecido el debate, al crear una dicotomía simple entre uno y otro régimen, al desconocer que es posible un punto intermedio para la capitalización colectiva de los recursos del sistema, todo esto bajo el modelo de prima media escalonada.

Aunque por su complejidad y amplitud tal perspectiva no puede ser desarrollada en este escrito, por ahora basta con señalar que es posible la construcción de una propuesta que recoja elementos de cada una de las directrices señaladas por las entidades. A modo de ejemplo, por qué no pensar en un modelo que permita cotizaciones y aportes flexibles, recaudo a través de 
medios masivos o contribuciones universales, inversión y rentabilidad de todos los dineros del sistema, beneficios proporcionales al aporte y complementados con otros beneficios no necesariamente económicos y, por qué no, pensiones universales.

\section{Referencias bibliográficas}

Arenas Monsalve, G. (2018). El derecho colombiano de la seguridad social. Bogotá: Legis Editores S.A.

Arrieta Mendoza, C. I. (2011). Las reformas del sistema pensional colombiano. Recuperado de: http://library.fes.de/pdf-files/bueros/kolumbien/08859.pdf

Asamblea Nacional Constituyente. (1991). Gacetas Constitucionales. Recuperado 13 de febrero de 2019, de Colegio de Abogados Rosaristas: http://abogadosrosaristas. org.co/2016/2016/10/19/gacetas-constitucionales/

Banco Interamericano de Desarrollo. (2019.). Quienes somos | IADB. Recuperado de: 1 de abril de 2019, de https://www.iadb.org/es/acerca-del-bid/quienes-somos

Banco Mundial. (1994). Envejecimiento sin crisis. Políticas para la protección de los ancianos y la promoción del crecimiento. Washington: Banco Mundial.

Blommestein, H. J. (1997). Institutional Investors, Pension Reform, and Emerging Securities Markets. SSRN Electronic Journal: IDB Working Paper No. 296, 1-52. Recuperada de: https://doi.org/10.2139/ssrn.1815985

Bosch, M., Berstein, S., Castellani, F., Oliveri, M. L. y Villa, J. M. (2015). Diagnóstico del sistema previsional colombiano y opciones de reforma. Inter-American Development Bank.

Burgos, G. (1999). Reforma judicial, desarrollo económico y banca multilateral. Revista Derecho del Estado, 12, 191- 202.

Castaño, H. (1992). Sobre la propuesta de reforma gubernamental al sistema pensional. Revista de Salud Pública Universidad de Antioquia, 12(1), 32-48.

Cetina Vargas, O. (1986). Derecho integral de seguridad social. Bogotá: Universidad Externado de Colombia.

Chaparro, S. (2015). La Ocde y el reduccionismo de la política laboral y pensional: Perspectivas: Friedrich Ebert Foundation, 36, 1-36. 
Congreso de la República de Colombia. (s. f.). Exposición de motivos proyecto de ley por la cual se crea el Sistema de Ahorro Pensional y se dictan otras disposiciones sobre seguridad social. Recuperado 19 de mayo de 2019, de https://normativa. colpensiones.gov.co/colpens/docs/pdf/xp_exm_I0100_93.pdf

Etala, J. J. (1966). Derecho de la seguridad social. Lecciones y Ensayos. Recuperado de: https://revistas-colaboracion.juridicas.unam.mx/index.php/lecciones-ensayos/ article/view/12793/11461

Girón, M. A. (1968). Seguridad social y protección de la salud. R.I.S.S.

Mesa-Lago, C. (1996). Las reformas de las pensiones en América Latina y la posición de los organismos internacionales. Revista CEPAL, (60), 73-94.

Morales, María. (2015). Los procesos de reformas y modificaciones a los sistemas de capitalización individual en América Latina. Biblioteca Jurídica UNAM.

OECD. (2015). Estudios económicos de la OCDE: Colombia 2015. Recuperado de: https:// doi.org/10.1787/9789264227682-es

Queisser, Monika. (1997). Pension reform and private pension funds in Peru and Colombia. Recuperado de: http://documents.worldbank.org/curated/ en/314771468757504570/pdf/multi-page.pdf

Sánchez, A. (2012). La seguridad y la protección social en México: su necesaria reorganización. México: UNAM.

Santa María, M., Steiner, R., Botero, J. H., Martínez, M., Millán, N., Schutt, E., \& Arias, M. A. (2010). El sistema pensional en colombia: retos y alternativas para aumentar la cobertura (p. 52). FEDESARROLLO. 